\title{
Inferências textuais para compreender textos multimodais: uma proposta interventiva
}

\section{Textual inferences to comprehend multimodal texts: an intervention proposal}

\author{
Rosimeri Mirta Fischer ${ }^{1}$ \\ Leandra Ines Seganfredo Santos ${ }^{2}$
}

DOI: $10.28998 / 2317-9945.2020 n 64 p 20-32$

\begin{abstract}
Resumo
Este artigo discorre sobre aspectos relativos à mediação e à melhora na compreensão leitora desenvolvidos no ambito do projeto de intervenção "Inferências textuais como estratégias metacognitivas: uma proposta de compreensão de textos multimodais"” proposto no Programa de Pós-graduação Profissional em Letras Profletras, Unemat, campus de Sinop/MT. A pesquisa tem como objetivo compreender como ocorre o processo de ativação ou construção de inferências textuais por meio de estratégias cognitivas e metacognitivas para a compreensão de textos multimodais. Para o desenvolvimento do projeto, utilizou-se a pesquisa qualitativa (BORTONI-RICARDO, 2008) associada ao método de pesquisa-ação (THIOLLENT, 1996). A produção de dados deu-se com atividades escritas, pausa protocolada, técnica do cloze, relato interpretativo digital e protocolos de leitura verbalizados. A pesquisa ocorreu na Escola Municipal Professor Jari Edgar Zambiasi, no municipio de Aripuanã/MT, com alunos do $9^{\circ}$ ano. Constatou-se que o projeto melhorou e ampliou a compreensão leitora dos estudantes, pois conseguiram ativar e produqiir inferências durante o desenvolvimento das atividades cognitivas e metacognitivas. Estas favorecem a reflexão sobre as informações construidas e a solução para problemas de compreensão textual e aquelas permitem a ativação do conhecimento armazenado na memória.
\end{abstract}

Palavras-chave: Inferências. Estratégias cognitivas e metacognitivas. Compreensão de textos multimodais

\begin{abstract}
This paper approaches some aspects related to mediaton and the improvement of reading comprehension developed in the intervention project "Textual inferences as metacognitive strategies: a proposal of multimodals texts comprehension", presented for the Programa de Pós-graduação Profissional em Letras - Profletras, Unemat, Sinop campus. It aims to understand how the activation, or the construction, of textual inferences take place by means of cognitive, or metacognitive, strategies for the multimodals texts comprehension. For the development of the project we used the qualitative research (BORTONI-RICARDO, 2008) associated with the action research method (THIOLLENT, 1996). The data was collected using writing activities,

\footnotetext{
${ }^{1}$ Mestra em Língua Portuguesa pelo Mestrado Profissional em Letras na Universidade do Estado de Mato Grosso, campus Sinop. Professora da rede pública de ensino.

2 Doutora em Linguística Aplicada pela Universidade Estadual Paulista. Professora adjunta da Universidade do Estado de Mato Grosso.

${ }^{3}$ Parecer consubstanciado número 1.931 .717 e todos os sujeitos envolvidos e seus responsáveis assinaram o Termo de Consentimento Livre e Esclarecido.
} 
protocoled reading, cloze procedure, digital interpretative account and reading aloud of reading protocols. The research took place at Escola Municipal Professor Jari Edgar Zambiasi, in the city of Aripuanã/MT, with students of 9th grade. The project improved and extended the student's reading comprehension, once they activated and produced inferences during the development of cognitive and metacognitive activities. These supported the reflection about the built informations and the solution to textual comprehension problems while those allow the activation of knowledge stored in memory.

Keywords: Inferences. Cognitive and metacognitive strategies. Multimodal texts comprehension

Recebido em: 07/02/2018.

Aceito em: 03/07/2018.

\section{Introdução}

Compreender textos é um desafio dos alunos e pessoas em geral. Essa dificuldade fica visível nos resultados das avaliações nacionais como a Prova Brasil. Devido à grande parte das pessoas não compreenderem textos de diversos gêneros, isso tem sido um empecilho para circularem em algumas esferas sociais, por não conseguirem realizar algumas funções linguísticas por elas exigidas.

Nessa perspectiva, Marcuschi (2008a, p. 230) afirma que "Para se ter uma ideia da dificuldade de compreender bem, basta considerar que, em menos da metade dos casos, as pessoas se saem a contento nos testes realizados em aula ou em concursos [...]". Diante desse contexto, verificamos a necessidade da construção de sentido por meio da compreensão, tanto do ouvinte quanto do leitor.

Vale ressaltar que para construir significados que levem à compreensão textual, o leitor parte de elementos linguísticos presentes na estrutura do texto que o remeterão aos demais conhecimentos que traz em sua memória, os quais foram cognitizados em uma relação sociointeracionista, interação que ocorre por meio da ativação ou construção de inferências no momento da leitura para que possa acontecer a compreensão.

Nesse sentido, esta pesquisa partiu do pressuposto da necessidade da compreensão textual, da relação entre elementos linguísticos e extralinguísticos, não verbais e semióticos, em textos multimodais para construção dos sentidos pela leitura.

A pesquisa teve cunho qualitativo por acreditar na necessidade de procurar entender como professora e alunos percebem a dificuldade de compreender textos multimodais como a propaganda. Além disso, a pesquisa qualitativa associada ao método de pesquisaação (THIOLLENT, 1996) permite o contato prolongado do pesquisador com o meio ambiente e o objeto de pesquisa, assim como coletar dados descritivos, permitindo o dinamismo nas situações de pesquisa (LÜDKE; ANDRÉ, 1986).

Diante do contexto da dificuldade de compreensão leitora dos alunos da Escola Municipal Professor Jari Edgar Zambiasi, em Aripuanã/MT, este trabalho visa compreender o processo de ativação ou construção de inferências textuais por meio de estratégias 
cognitivas e metacognitivas para a compreensão de textos multimodais no gênero propaganda, com uma proposta que se inscreve na linha de pesquisa "Teorias da Linguagem e Ensino" e na Linguística Textual, em um diálogo com a teoria cognitiva.

A melhoria na aprendizagem da leitura e da escrita do ensino fundamental tem sido uma das preocupações do Governo Federal nos últimos anos, prova disso são projetos de aperfeiçoamento dos professores como o Profletras (Programa de Pós-Graduação Profissional em Letras). Programas como este visam capacitar os professores para que possam permear pelas áreas de linguagem com maturidade intelectual, amparados em teorias e instigados às pesquisas interventivas em sala de aula, com o intuito de sanar problemas encontrados na aprendizagem dos estudantes. Referente ao Profletras, Santos (2016) assevera que:

O Programa adota uma perspectiva transdisciplinar abalizado em múltiplas tendências teórico-metodológicas no intento de formar docentes de LP volvidos para a inovação na sala de aula. Espera-se, também, despertar uma postura de professor-pesquisador que, enquanto realiza as propostas de intervenção, reflita sobre diferentes usos da linguagem na sociedade (SANTOS, 2016, p. 21).

Nesse sentido, os professores recebem suporte que enriquece sua prática profissional com vistas à proficiência leitora e escritora de alunos do ensino fundamental por meio de atividades que envolvam letramento e gêneros discursivos (BRASIL, 2013). Consoante Bakhtin (2010, p. 262), "A riqueza e a diversidade dos gêneros do discurso são infinitas porque são inesgotáveis as possibilidades da multiforme atividade humana [...]". Dessa forma, ampliam-se as habilidades leitoras e escritoras dos alunos em uma sociedade basicamente letrada, voltando às atividades de sala aos gêneros discursivos.

Sob essa égide, o artigo transcorre sobre um projeto interventivo conforme prevê a proposta do Profletras, voltado para a ativação ou construção de inferências textuais por meio de estratégias cognitivas e metacognitivas para a compreensão de textos multimodais (propaganda).

A intervenção ocorreu por meio de atividades de compreensão de textos multimodais de questões cognitivas e metacognitivas com enfoque em inferências lógicas, avaliativas, elaborativas, informativas e socioculturais, as quais foram delimitadas para essa pesquisa. Outra proposta interventiva do trabalho foram os protocolos de leitura verbal, tanto o concorrente quanto o retrospectivo, que proporcionou a mediação através de andaimes produzidos durante o desenvolvimento da atividade compreensiva inferencial.

\section{Metodologia}

Como já mencionado, a pesquisa é de cunho qualitativo, pois procurou entender, interpretar o processo e o contexto de ensino-aprendizagem percebendo a dificuldade de compreensão de textos multimodais (BORTONI-RICARDO, 2008). Também se associa ao método da pesquisa-ação de Michel Thiollent (1996). Nesse sentido, Toledo e Jacobi (2013) corroboram ao afirmarem que a pesquisa-ação oferece subsídios através da interação entre o pesquisador e os sujeitos da pesquisa para encontrar respostas e soluções que promovam transformação ao mobilizar novas práticas. 
As novas práticas ocorreram por meio de atividades de compreensão de textos multimodais - propagandas -, a produção de um relato interpretativo digital pelos alunos, pausa protocolada, técnica do cloze e protocolos de leitura em horário extraclasse com alunos de maior e menor dificuldade interpretativa para verificação do processo cognitivo e metacognitivo de ativação ou produção de inferências no momento da leitura compreensiva.

O local escolhido para a pesquisa foi a Escola Municipal Professor Jari Edgar Zambiasi, a qual é pequena, atende em torno de 500 alunos nos períodos matutino e vespertino com turmas de $5^{\circ}$ ao $9^{\circ}$ ano e no noturno com turmas de EJA (Educação de Jovens e Adultos) dos segmentos iniciais (alfabetização até $5^{\circ}$ ano). Os alunos residem em bairros nos entornos da escola e alguns vêm com o transporte escolar de sítios e fazendas próximos da cidade. A maioria é de baixa renda e ficam sozinhos ou com irmãos menores em suas casas durante o dia, enquanto os pais trabalham.

A escolha aconteceu devido aos problemas relacionados à compreensão de textos nos diferentes tipos, gêneros e suportes. Sob essa égide, considerou-se necessário o desenvolvimento de um projeto que se voltasse para o problema citado, uma vez que compreender textos é importante tanto para a vida social quanto escolar. Além disso, os índices dos resultados de avaliações nacionais como a Prova Brasil revelam a importância de se buscar resultados favoráveis para os alunos e para a escola.

O planejamento da aula foi baseado em Menegolla e Sant'Anna (2014), que leva em consideração o professor, os alunos, os conteúdos, as experiências, as atividades e os objetivos no momento de planejar. O projeto foi desenvolvido durante os dois primeiros bimestres do ano letivo de 2017, no horário das aulas de Língua Portuguesa, contando com o auxílio da equipe gestora da escola, da professora regente da sala, dos alunos e seus pais que autorizaram a pesquisa.

\section{Compreensão de textos e inferências}

A compreensão de textos é um tema complexo, pois envolve diversos elementos que compõem a cognição e intelectualidade humana. Para Marcuschi (2008a, p. 230), “Compreender não é uma ação apenas linguística ou cognitiva. É muito mais uma forma de inserção no mundo e um modo de agir sobre o mundo na relação com o outro dentro de uma cultura e uma sociedade". Portanto, para que a compreensão ocorra é preciso uma interação entre elementos linguísticos e extralinguísticos.

Nessa perspectiva, as inferências são salutares, visto que, segundo Koch (2009), possibilitam gerar informações semânticas novas, funcionam como estratégias cognitivas para novas representações mentais, tornando o texto coerente para o leitor ou ouvinte. Além disso, são provedoras de contexto integrador ao estabelecer coerência para o leitor durante a leitura do texto.

O envolvimento entre autor-texto-leitor durante a compreensão por meio de inferências possibilita uma ação interativa entre contextos socioculturais, uma vez que são acionados diversos conhecimentos prévios como os linguísticos ou históricos, esquemas cognitivos que fazem parte das leituras e vivências do leitor. 
Para Solé (1998), a compreensão durante a leitura envolve não só a capacidade de decodificação, de ter objetivos para a leitura, acionar ideias e experiências prévias, mas envolve um processo de previsão e inferenciação. Nessa perspectiva interativa, a compreensão se dá como construção coletiva, já que envolve vários conhecimentos que são partilhados e se complementam.

A cognição só é um aspecto automático e inconsciente por ser um "processo mental de apreensão, processamento e recuperação de conhecimento" (POERSCH, 1998 apud CHAVES; LOPES, 2012, p. 22). Nesse sentido, na teoria do processamento de informações na memória a curto prazo, depois de ativado e atualizado, o conhecimento passa para a memória episódica e depois segue para a memória a longo prazo. Esta última armazena as informações que são alocadas para serem ativadas no momento oportuno e contribuem com a compreensão por meio de inferências (VAN DIJK, 2013).

Durante a leitura, espera-se que se ative o conhecimento construído e armazenado na memória para que haja compreensão, que pode ocorrer por meio da criação de hipóteses, que podem ser refutadas ou validadas no decorrer do processo leitor. Kleiman (1999, p. 43) corrobora com essa ideia quando afirma que "na testagem de hipóteses, estará reconstruindo uma estrutura textual; na predição ele estará ativando seu conhecimento prévio, e na testagem ele estará enriquecendo, refinando, checando esse conhecimento". Nesse contexto, há as inferências ligadas ao conhecimento de mundo e o conhecimento organizado em esquemas que são inconscientes, portanto, aspectos cognitivos que funcionam como proposições de inferenciação (KLEIMAN, 1999).

Segundo Van Dijk (2013), os esquemas contribuem com o processamento cognitivo da informação. Para Kleiman (1999), os esquemas favorecem a economia lexical e comunicacional ao se estruturarem os assuntos, situações e eventos na memória em termos. Dessa forma, ocorre a inferenciação no momento da compreensão, pois remetem a um contexto, ocasionando a cognição. No entanto, ao refletir sobre a veracidade da hipótese ou a contextualização dos esquemas, o leitor remete ao processo de metacognição.

A metacognição diferencia-se do processo cognitivo por possuir aspectos conscientes, tendo assim, a capacidade de monitorar e autorregular a cognição (JOU; SPERB, 2006). Voltados para o processo metacognitivo há os objetivos de leitura e a formulação de hipóteses que, para Kleiman (1999), são atividades que pressupõem reflexão e controle consciente sobre o próprio conhecimento.

Portanto, o trabalho voltado às inferências como elementos linguísticos ou extralinguísticos é reconhecer que elas funcionam como hipóteses ou estratégias, que possibilitam a construção de representações semânticas e informacionais a partir do contexto.

\section{Uma proposta interventiva para a leitura do texto multimodal}

Com o avanço tecnológico, os textos que circulam na sociedade constituem-se e estruturam-se por semioses que os tornam multimodais. Marcuschi (2008a, p. 80) assevera que "o texto é construído numa orientação de multissistemas, ou seja, envolve tanto aspectos linguísticos como não linguísticos no seu processamento (imagem, música) e o texto se torna em geral multimodal". Nessa conexão dos vários elementos que compõem a 
multimodalidade, ocorre uma interação e uma multifuncionalidade que necessita de certos conhecimentos para ampliar a compreensão textual, já que há combinações entre sons, imagens, palavras, cores, texturas e tantos outros componentes desse mosaico multissemiótico.

$\mathrm{Na}$ perspectiva multimodal, as formas verbal e não verbal complementam-se numa interação entre texto escrito, que não significa mais isoladamente, e os elementos semióticos, contribuindo para o desenvolvimento da cognição humana (SILVA; RODRIGUES, 2014). Além disso, vale ressaltar que a interação humana acontece por meio de gêneros, que fluem de maneira multimodal como afirma Marcuschi (2008b):

[...] os gêneros se configuram de maneira plástica e não formal; são dinâmicos, fluindo um do outro e se realizando de maneira multimodal; circulam na sociedade das mais variadas maneiras e nos mais variados suportes. Exercem funções sócio-cognitivas e permitem lidar de maneira mais estável com as relações humanas em que entra a linguagem (MARCUSCHI, 2008b, p. 20).

Os textos multimodais voltados para as teorias cognitivas são tratados por Dionísio e Vasconcelos (2013) ao apresentarem a Teoria Cognitiva de Aprendizagem Multimodal (TCAM) de Richard Mayer. Na TCAM, foram ressaltados na pesquisa os dois canais de processamento de informação - verbal e visual -, os tipos de memória envolvidos e o pensamento ativo do estudante no desenvolvimento das atividades.

$\mathrm{Na}$ aplicação da técnica do cloze, a maioria dos alunos conseguiu inferir as palavras que seriam exatas ou semanticamente parecidas com as que viram no texto da propaganda trabalhada para essa atividade. Sob essa égide, é possível considerar que realizaram uma atividade metacognitiva, uma vez que refletiram e controlaram conscientemente o seu conhecimento armazenado na memória e resgatado para preencher adequadamente os espaços propostos na atividade (SOLÉ, 1998):

Fragmento 1: atividade de cloze da aluna E - $9^{\circ}$ A da EM Professor Jari Edgar Zambiasi de Aripuanã/MT.

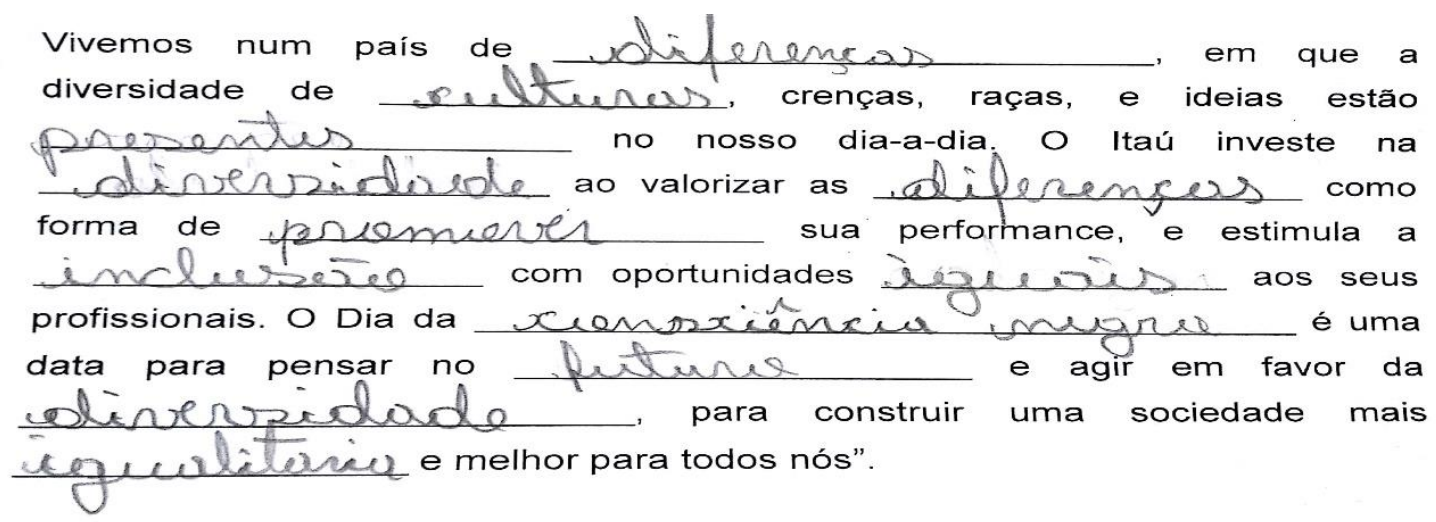

Fonte: Fischer, 2018, p. 72.

Na propaganda em vídeo, foi possível observar a relevância de se considerar os dois canais no desenvolvimento de uma das atividades. Segundo as apreciações dos alunos, essa atividade foi bem mais interessante que as demais, razão pela qual foram bem participativos, o que comprova o princípio da modalidade de Mayer (2009), pois não houve sobrecarga dos 
canais - auditivo e visual -, uma vez que utilizaram os dois, dessa maneira palavras e imagens não entraram pelo mesmo sistema cognitivo.

A propaganda foi o vídeo Top 10 Os melhores comerciais de todos os tempos ${ }^{4}$ - parte 3 e o produto divulgado é da Pantene, produtos para cabelos. Nesse vídeo realizou-se a pausa protocolada, por estar em forma de narrativa, mas desde o início se oferecem pistas implícitas sobre o produto. Vale ressaltar que a combinação de elementos semióticos e linguísticos como cores, imagens, som, palavras escritas - pois as personagens não dialogam, porém as ações corroboram para a produção de sentidos do texto - constituem a multimodalidade dessa propaganda.

A narrativa relata o sonho e as dificuldades de uma menina em ser bailarina e a contribuição de sua avó para concretizá-lo, com enfoques nos cabelos da criança, que passa para a adolescência culminando na sua vitória em uma seletiva de bailarinas, na qual ela deixa os cabelos longos, soltos, demonstrando toda a beleza proporcionada pelos produtos Pantene.

Durante o vídeo aconteceram pausas e os alunos escreveram as suas hipóteses ligadas ao produto, às inferências lógicas, avaliativas, informativas e elaborativas, bem como as socioculturais e as entregaram à professora pesquisadora. Após concluírem a pausa protocolada, todos assistiram ao vídeo sem interrupções e discutiram sobre suas hipóteses; nesse momento foi possível refutá-las ou tomá-las como verdadeiras.

Nessa proposta, os alunos envolveram-se mais, participaram e debateram, comprovando que quando se usa os canais visual e auditivo, sem sobrecarga, a aprendizagem acontece com mais fluidez, ressaltando os recursos tecnológicos para a aprendizagem (BARBOSA; REINALDO, 2014).

No decorrer dessa atividade, trabalhou-se com estratégias cognitivas - questões que traziam à tona conhecimentos adquiridos - e metacognitivas, porque os estudantes produziram hipóteses sobre qual seria o produto que estava anunciado no vídeo, assim como o lugar em que se passava a narrativa, entre outros elementos. Os esquemas mentais ativados, de um modo geral, referiram-se a produtos para cabelo, como xampu e condicionadores, embora as hipóteses sobre a marca tenham sido refutadas no final do vídeo (KLEIMAN, 1999).

Fragmento 2: respostas das questões 1, 2, 3 e 4 da aluna G - $9^{\circ}$ A da EM Professor Jari Edgar Zambiasi de Aripuanã/MT.

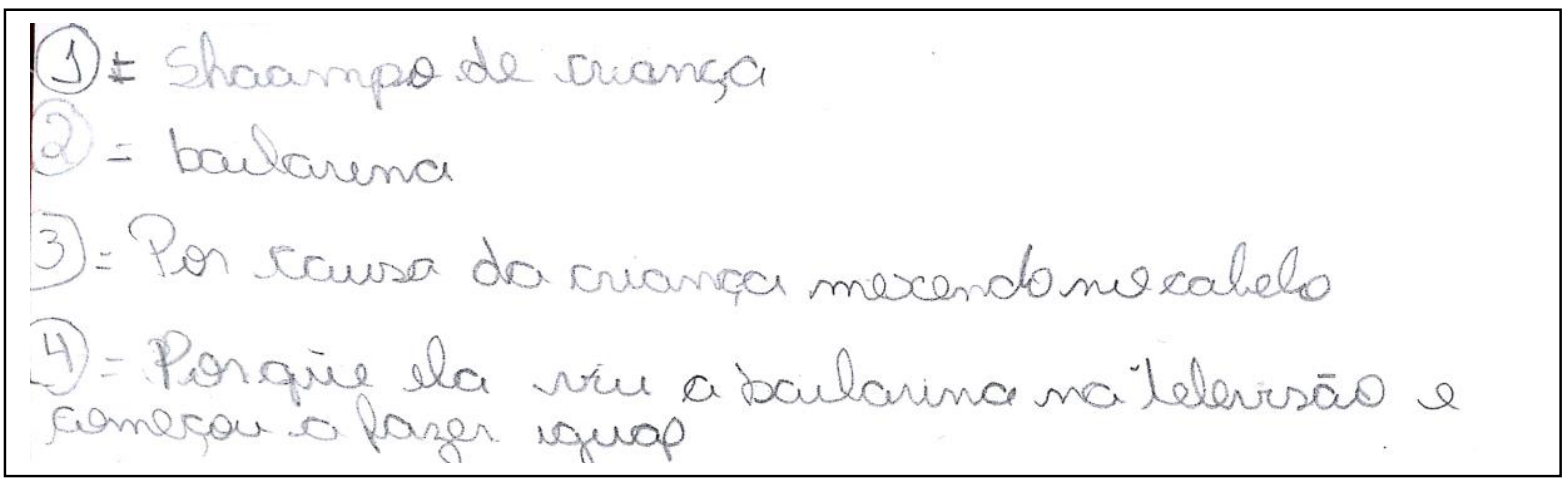

${ }^{4}$ Disponível em: <https://www.youtube.com/watch?v=KF21ALqhGjY>. Acesso em: 18 set. 2018. 
Fonte: Fischer, 2018, p. 74.

Além disso, suscitaram-se as inferências lógicas que estão voltadas para as causas e consequências dos fatos, eventos e emoções presentes no texto e são ligações em uma cadeia causal (DELL'ISOLA, 1988), como pode ser constatado na resposta da questão quatro do fragmento anterior. Também se destacaram as inferências elaborativas, por acionarem conhecimentos prévios para preencher as lacunas no texto para descobrir o produto informado - "shampoo de criança".

Outra inferência observada foi a informativa, por estabelecer referência do texto com o contexto espaço-temporal dos eventos: “Quem? O quê? Quando? Onde?” (DELL'ISOLA, 1988). As inferências socioculturais foram acionadas durante o desenvolvimento das atividades porque, para Dell'Isola (1988), estão ligadas às experiências, à classe social, à vivência pessoal de cada aluno. Essas constatações podem ser verificadas nos relatos contidos nos fragmentos das alunas $G, F$ e A.

Fragmento 3: relato interpretativo das alunas G e E - 9o A da EM Professor Jari Edgar Zambiasi de Aripuanã/MT.

Assistimos um vídeo sobre um shampoo, no começo parecia propaganda de aula de balé, mas no decorrer do vídeo fomos percebendo que era de shampoo da Pantene e na propaganda mostrava que se nós usarmos o produto da Pantene ficariamos poderosas e superaríamos qualquer obstáculo.

Fonte: Fischer, 2018, p. 75.

Vale salientar a relevância da construção de inferências durante a compreensão leitora, bem como considerar os textos multimodais como combinação de gêneros e subsidiar nos elementos cognitivos fatores profícuos para a ampliação compreensiva, voltando-se para os modos semióticos existentes na tessitura das propagandas impressas, digitais ou em vídeos.

Embora os termos "propaganda" e "publicidade" sejam distintos em suas significações, pois publicidade volta-se mais para o âmbito comercial e propaganda para o ideológico, neste trabalho usou-se o termo propaganda tanto para a propagação de ideias e ideologias quanto para o comercial de produtos, porque mesmo quando se pretende anunciar um produto as ideologias ficam subentendidas na escolha linguística.

Havia sido programado produzir o relato interpretativo digital após a aplicação de cada planejamento de aula, no entanto, houve alguns imprevistos, como o empréstimo da sala de informática para acadêmicas de Pedagogia de ensino à distância de uma faculdade particular. Infelizmente um desses momentos ocorreu em um dos dias de aplicação do projeto.

Outro fator que alterou essa atividade foi a falta de computadores, pois alguns estavam danificados e os alunos precisaram juntar-se em grupos de 3 estudantes para cada computador, enquanto dois grupos ainda aguardavam até que outros desocupassem as máquinas. Em outro momento, a diretora da escola pediu um tempo da aula para conversar com os alunos alguns assuntos pendentes sobre uma confraternização entre turmas dos $9^{\circ}$ anos da escola e para isso precisavam se organizar e distribuir tarefas.

Outra questão que influenciou no andamento das atividades foram alguns alunos que respondiam as questões de forma evasiva, como "sim" ou "não", sem discorrer sobre suas 
respostas. A maioria dos alunos do $9^{\circ}$ ano A matutino eram alunos anteriormente comprometidos com sua aprendizagem e suas tarefas, mas, quando chegaram a essa série/ano, ficaram evasivos e alguns até com problemas no comportamento em sala, atitudes incomuns em outros anos.

Para a realização dos protocolos de leitura em horário diferenciado do período de aula dos alunos, a coordenação indicou alguns com dificuldade compreensiva nos anos anteriores, no entanto, apenas três participaram, mas faltavam muito nos dias marcados. $\mathrm{Na}$ verdade, realizaram poucas atividades, visto que diziam não poder ir sempre. Entretanto, foi possível perceber que quando realizada a mediação e a produção de andaimes esses alunos conseguiam responder, produzindo ou ativando inferências.

Segundo Magalhães e Machado (2012), andaime é um termo metafórico que indica uma ajuda que uma pessoa mais experiente proporciona a um aprendiz para que este amplie suas capacidades. De acordo com as teorias de mediação de Vygotsky (2008), o processo de andaimes acontece pela mediação, uma interação do aprendiz com seu par mais experiente e com o objeto de conhecimento, na qual ocorre uma relação de transferência e apoio entre ambos, a qual o autor citado denominou de zona de desenvolvimento proximal.

A mediação ficou visível durante o trabalho com protocolos verbais de leitura porque se averiguaram as estratégias elaboradas pelos estudantes leitores no momento da leitura para buscar a compreensão do texto. Como se verifica na mediação que o aluno recebeu para que construísse um sentido para a palavra seleto, a partir de conhecimentos prévios, que foram ativados durante a atividade no protocolo a seguir.

Fragmento 4: protocolo de leitura verbal do aluno A - 9 $9^{\circ}$ A da EM Professor Jari Edgar Zambiasi de Aripuanã/MT.

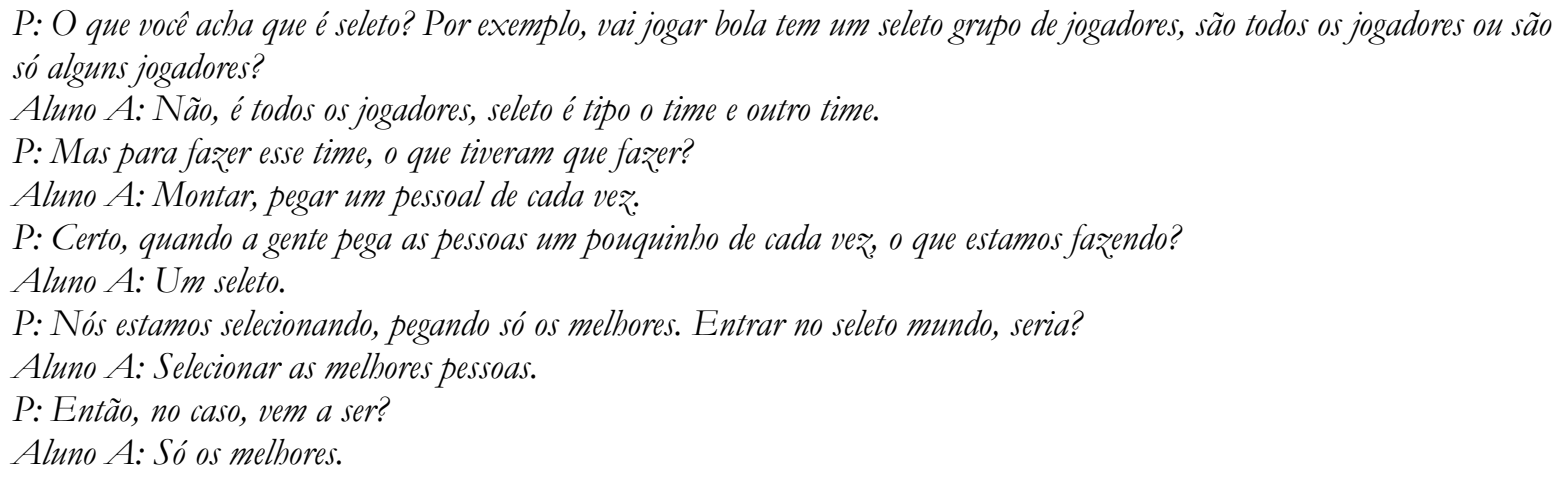

P: O que você acha que é seleto? Por exemplo, vai jogar bola tem um seleto grupo de jogadores, são todos os jogadores ou são só alguns jogadores?

Aluno A: Não, é todos os jogadores, seleto é tipo o time e outro time.

P: Mas para fazer esse time, o que tiveram que fazer?

Aluno A: Montar, pegar um pessoal de cada vez:

P: Certo, quando a gente pega as pessoas um pouquinho de cada vez, o que estamos fazendo?

Aluno A: Um seleto.

P: Nós estamos selecionando, pegando só os melhores. Entrar no seleto mundo, seria?

Aluno A: Selecionar as melhores pessoas.

$P:$ Então, no caso, vem a ser?

Aluno A: Só os melhores.

Fonte: Fischer, 2018, p. 96.

Também foi possível observar, no momento da verbalização, as dificuldades dos alunos nos itens tanto lexicais como de decodificação, além de poder ocorrer a construção de andaimes através da mediação do professor, com perguntas e outros procedimentos que auxiliem na compreensão. Magalhães e Machado (2012) asseveram que:

a mediação pedagógica é extremamente relevante para o processo de formação leitora, ainda mais quando se recorre aos protocolos verbais como metodologia para investigar a leitura. Os protocolos verbais servem para registro, reflexão e tomada de decisões de como avançar na sala de 
aula quando o assunto são estratégias de leitura (MAGALHÃES; MACHADO, 2012, p. 63).

Já os alunos com eficiência leitora faltaram menos às atividades de protocolo e ativaram inferências lógicas, elaborativas, avaliativas, informativas e socioculturais durante a leitura, ressaltando que o processo de inferenciação é considerado cognitivo, uma vez que estão alocadas na memória e são ativadas de forma inconsciente. Os estudantes também participaram do processo metacognitivo que ocorria com eles durante a compreensão ao explanar suas estratégias para compreender termos, palavras e situações. Segundo o aluno B, a partir das observações ele reflete sobre a resposta mais adequada à questão sugerida, o que pode ser visualizado no protocolo de leitura verbal do aluno citado.

Fragmento 5: protocolo de leitura verbal do aluno B - 9o A da EM Professor Jari Edgar Zambiasi de Aripuanã/MT.

P: Quando você não consegue entender algo no texto, como você faž, em sua mente, para tentar entender? Aluno B: Eu vejo mais a imagem, busco mais ler tudo primeiro pra depois responder as perguntas. Vejo as imagens e presto atenção na frase. Interpretar a frase e ver o logotipo.

Fonte: Fischer, 2018, p. 99.

Após a conclusão de todas as atividades, os alunos puderam expor suas opiniões sobre a aplicação do projeto; se o consideraram relevante, se contribuiu para a ampliação da compreensão textual, principalmente de textos multimodais - propagandas -, e salientaram que aprenderam muito não só com as atividades, mas também com as interações entre os colegas que sabiam alguns assuntos que favoreciam as respostas, com os debates e com a intervenção da professora pesquisadora.

A afetividade entre todos foi ampliada e novas amizades surgiram, houve uma troca de conhecimentos, de experiências, de vivências. Isso só foi possível porque quando se une teoria e prática ao trabalho escolar proporciona-se a criação de estratégias de ensino para transformar os aspectos negativos, que parecem intransponíveis, em evidências que levem à reflexão não só individual, mas coletiva sobre a prática educativa.

\section{Conclusão}

O desenvolvimento desta pesquisa expôs a importância de propostas que busquem soluções para problemas de aprendizagem que não são individuais, mas coletivos - a dificuldade na compreensão leitora dos alunos. Essa constatação demonstra a relevância do Profletras para a educação não só de Aripuanã, mas do Mato Grosso e do Brasil, pois o professor mestrando leva à pós-graduação o anseio por metodologias, teorias que solucionem os problemas de aprendizagem de seus alunos. Nessa perspectiva, deparam-se com disciplinas ancoradas em teorias que permitem reflexões sobre as práticas de ensino e o caminho teórico a ser trilhado para alcançar êxito em suas aulas.

O projeto "Inferências textuais como estratégias metacognitivas: uma proposta de compreensão de textos multimodais" desenvolveu atividades que possibilitaram a ativação e a produção de inferências. Vale ressaltar que quando os alunos respondiam as questões, eles voltavam-se para os aspectos cognitivos ao buscarem em suas memórias conhecimentos de 
aulas de ciências, história, ou das relações familiares e socioculturais para preencher lacunas e produzir sentido ao texto.

No entanto, nos momentos de incerteza sobre as respostas elaboravam hipóteses, consideradas metacognição, por serem reflexões construídas a partir de conhecimentos armazenados na memória, que podem ser válidos ou refutáveis.

As atividades cognitivas e metacognitivas favoreceram, também, a mediação entre os pares - alunos-alunos, professor-aluno -, uma vez que, durante as discussões, havia uma troca de conhecimentos adquiridos e debates sobre a relevância da ativação dessas informações no momento da leitura.

Dessa forma, pode-se dizer que essa pesquisa contribuiu tanto para a verificação da necessidade de se ativar ou produzir inferências durante a leitura para que haja compreensão, quanto para que os professores se tornem pesquisadores em busca de soluções para problemas de aprendizagem nas diversas disciplinas e melhorias para suas práticas educacionais.

Além disso, os estudantes verificaram suas melhorias e ampliações sobre a compreensão de textos multimodais - propagandas -, quando verificaram em atividade sequentes uma melhor compreensão de textos que envolvam tantas semioses, porque ativaram mais conhecimentos e percepções do que o texto escrito. Nesse sentido, verificouse que as teorias cognitivas podem contribuir para a aprendizagem dos estudantes e também a necessidade da valorização da pesquisa na escola para o desenvolvimento do fazer pedagógico.

\section{Referências}

BAKHTIN, M. M. Estética da criação verbal. 5 ed. São Paulo: Martins Fontes, 2010.

BARBOSA, Flávia Karolina L. D.; REINALDO, Maria Augusta G. M. Deslocamento de contexto disciplinar e aprendizagem multimodal no Ensino Médio Integrado. Anais do VI Simpósio Internacional de Ensino da Língua Portuguesa, v. 4, n. 1. Uberlândia: EDUFU, 2014. Disponível em: http://www.ileel.ufu.br/anaisdosielp/wpcontent/uploads/2014/11/895.pdf. Acesso em: 18 set. 2018.

BORTONI-RICARDO, Stella Maris. O professor pesquisador: introdução à pesquisa qualitativa. São Paulo: Parábola Editorial, 2008.

BRASIL. Proposta Profletras. 2013. Disponível em: https://sucupira.capes.gov.br/sucupira/public/consultas/coleta/programa/viewPrograma .jsf?popup=true\&cd_programa=23001011069P5. Acesso em: 18 set. 2018.

CHAVES, Jésura; LOPES, Marília. Metacognição e Metalinguagem. In: PEREIRA, V. W.; GUARESI, R. (org.). Estudos sobre leitura: psicolinguística e interfaces. Porto Alegre: EDIPUCRS, 2012, p. 21-30.

DELL' ISOLA, Regina Lúcia Péret. Leitura: inferências e contexto sociocultural. Dissertação (Mestrado em Letras) - Universidade Federal de Minas Gerais, Belo 
Horizonte, 1988. Disponível em:

http://www.bibliotecadigital.ufmg.br/dspace/handle/1843/BUBD-9DWEUQ. Acesso em: 18 set. 2018.

DIONÍSIO, Angela Paiva; VASCONCELOS, Leila Janot de. Multimodalidade, gênero textual e leitura. In: BUNZEN, Clecio; MENDONÇA, Márcia (org.). Múltiplas linguagens para o ensino médio. São Paulo: Parábola Editorial, 2013.

FISCHER, Rosimeri Mirta. Inferências textuais como estratégias metacognitivas: uma proposta de compreensão de textos multimodais. Trabalho de Conclusão Final (Mestrado Profissional em Letras) - Universidade do Estado de Mato Grosso, Sinop, 2018.

JOU, Graciela Inchausti de; SPERB, Tania Mara. A metacognição como estratégia reguladora da aprendizagem. Psicologia: reflexão e crítica, v. 19, n. 2, p. 177-185, 2006.

KLEIMAN, Angela. Texto e leitor: aspectos cognitivos da leitura. Campinas: Pontes, 1999.

$\mathrm{KOCH}$, Ingedore Grunfeld Villaça. Introdução à linguística textual: trajetória e grandes temas. São Paulo: Martins Fontes, 2009.

LÜDKE, Menga; ANDRÉ, Marli E. D. A. Pesquisa em educação: abordagens qualitativas. São Paulo: EPU, 1986.

MAGALHÃES, Rosineide; MACHADO, Veruska Ribeiro. Leitura e interação no enquadre de protocolos verbais. In: BORTONI-RICARDO, S. M. et al. (org.). Leitura e mediação pedagógica. São Paulo: Parábola Editorial, 2012, p. 45-64.

MARCUSCHI, Luiz Antônio. Produção textual, análise de gêneros e compreensão. São Paulo: Parábola Editorial, 2008a.

MARCUSCHI, Luiz Antônio. Gêneros textuais: configuração, dinamicidade e circulação. In: KARWOSKI, Beatriz Gaydeczka; SIEBENEICHER, Brito (org.) Gêneros textuais: reflexões e ensino. 3 ed. Rio de Janeiro: Nova Fronteira, 2008b, p. 15-28.

MAYER, Richard E. Multimedia Learning. 2 ed. New York: Cambridge University Press, 2009.

MENEGOLLA, Maximiliano; SANT’ANNA, Ilza Martins. Por que planejar? Como planejar? Currículo, área, aula. 22 ed. Petrópolis: Vozes, 2014.

SANTOS, Leandra Ines Seganfredo. Unidades mato-grossenses do PROFLETRAS: abrangência, resultados e perspectivas. Letras \& Letras, Uberlândia, v. 32, n. 2, p. 16-45, jul./dez. 2016.

SILVA, Maria Gorette Andrade; RODRIGUES, Linduarte Pereira. Multimodalidade e ensino: (re)descobrindo os sentidos na interação entre linguagens. Congresso

Internacional de Educação e Inclusão (CINTEDI). 2014. Disponível em: http://editorarealize.com.br/revistas/cintedi/trabalhos/Modalidade_1datahora_02_11_20 14_17_15_59_idinscrito_113_29f3c3a2d034cf2415a17d8a5f0b683c.pdf. Acesso em: 18 set. 2018. 
SOLÉ, Izabel. Estratégias de leitura. 6 ed. Trad. Claudia Schilling. Porto alegre: Penso, 1998.

THIOLLENT, Michel. Metodologia da pesquisa-ação. 7 ed. São Paulo: Cortez, 1996.

TOLEDO, Renata Ferraz de; JACOBI, Pedro Roberto. Pesquisa-ação e educação: compartilhando princípios na construção de conhecimentos e no fortalecimento comunitário para o enfrentamento de problemas. Educação \& Sociedade, Campinas, v. 34, n. 122, jan./mar. 2013. Disponível em:

http://www.scielo.br/scielo.php?script=sci_arttext\&pid=S0101 -

$73302013000100009 \& \operatorname{lng}=$ en\&nrm=iso\&tlng=pt. Acesso em: 18 set. 2018.

VAN DIJK, Teun Adrianus. Cognição, discurso e interação. 7 ed. Organização e apresentação: Ingedore V. Koch. São Paulo: Contexto, 2013.

VYGOTSKY, Lev Semenovich. Pensamento e linguagem. 4 ed. Trad. Jefferson Luiz Camargo. São Paulo: Martins Fontes, 2008. 